\title{
Cognitive function in postmenopausal breast cancer patients one year after completing adjuvant endocrine therapy with letrozole and/or tamoxifen in the BIG 1-98 trial
}

\author{
Kelly-Anne Phillips · Julie Aldridge $\cdot$ Karin Ribi - Zhuoxin Sun • \\ Alastair Thompson - Vernon Harvey • Beat Thürlimann • Fatima Cardoso • \\ Olivia Pagani · Alan S. Coates • Aron Goldhirsch • Karen N. Price • \\ Richard D. Gelber · Jürg Bernhard
}

Received: 13 October 2010/ Accepted: 18 October 2010/Published online: 3 November 2010

(C) Springer Science+Business Media, LLC. 2010

\begin{abstract}
Endocrine therapy for breast cancer may affect cognition. The purpose of this study was to examine whether cognitive function improves after cessation of adjuvant endocrine therapy. Change in cognitive function was assessed in 100 postmenopausal breast cancer patients in the BIG 1-98 trial, who were randomized to receive 5 years of adjuvant tamoxifen or letrozole alone or in
\end{abstract}

K.-A. Phillips

Peter MacCallum Cancer Centre, The University of Melbourne,

Melbourne, VIC, Australia

e-mail: Kelly.Phillips@petermac.org

J. Aldridge $\cdot$ Z. Sun

IBCSG Statistical Center, Dana-Farber Cancer Institute,

Boston, MA, USA

e-mail: julie@jimmy.harvard.edu

Z. Sun

e-mail: zhuoxin@jimmy.harvard.edu

K. Ribi

IBCSG Coordinating Center, Bern, Switzerland

e-mail: karin.ribi@ibcsg.org

\section{A. Thompson}

Ninewells Hospital, University of Dundee, Dundee,

Scotland, UK

e-mail: a.m.thompson@dundee.ac.uk

V. Harvey

Auckland City Hospital, Auckland, New Zealand

e-mail: VernonH@adhb.govt.nz

\section{Harvey}

Australian New Zealand Breast Cancer Trials Group,

Newcastle, Australia

B. Thürlimann

Breast Center, Kantonsspital, St. Gallen, Switzerland

e-mail: beat.thuerlimann@kssg.ch sequence. Cognitive function was evaluated by computerized tests during the fifth year of trial treatment (Y5) and 1 year after treatment completion (Y6). Cognitive test scores were standardized according to age-specific norms and the change assessed using the Wilcoxon signed-rank test. There was significant improvement in the composite cognitive function score from Y5 to Y6 (median of

B. Thürlimann · O. Pagani

Swiss Group for Clinical Cancer Research (SAKK),

Bern, Switzerland

e-mail: olivia.pagani@ibcsg.org

F. Cardoso

Department of Medical Oncology, Jules Bordet Institute,

Brussels, Belgium

e-mail: fatimacardoso@fundacaochampalimaud.pt

O. Pagani

Oncology Institute of Southern Switzerland, Ospedale Italiano,

Viganello, Lugano, Switzerland

A. S. Coates

International Breast Cancer Study Group, Bern, Switzerland e-mail: alan.coates@ibcsg.org

A. S. Coates

University of Sydney, Sydney, Australia

A. Goldhirsch

Department of Medicine, European Institute of Oncology,

Milan, Italy

e-mail: aron.goldhirsch@ibcsg.org

A. Goldhirsch

Oncology Institute of Southern Switzerland,

Bellinzona, Switzerland 
change $=0.22$, effect size $=0.53, \quad P<0.0001)$. This improvement was consistent in women taking either tamoxifen or letrozole at Y5 $(P=0.0006$ and $P=0.0002$, respectively). For postmenopausal patients who received either adjuvant letrozole or tamoxifen alone or in sequence, cognitive function improved after cessation of treatment.

Keywords Cognitive function - Breast cancer . Aromatase inhibitor · Tamoxifen - Letrozole . Quality of life

\section{Introduction}

Most postmenopausal early stage breast cancer patients have hormone receptor-positive disease and are, therefore, treated with endocrine therapy [1]. Several studies suggest that adjuvant endocrine therapy is associated with impaired cognitive function during treatment [2-5], and that tamoxifen may have a more adverse effect than aromatase inhibitors [2, 6, 7]. No published study has specifically evaluated the trajectory of cognitive function after ceasing adjuvant endocrine therapy. We evaluated the change in cognitive function 1 year after cessation of adjuvant endocrine therapy in a subgroup of postmenopausal earlystage breast cancer patients treated in the BIG 1-98 trial.

\section{Methods}

The BIG 1-98 trial (March 1998-May 2003) randomized 8010 postmenopausal women with hormone receptorpositive tumors to receive one of four adjuvant endocrine therapy options after stratification by institution and chemotherapy (Fig. 1) [8, 9]. A substudy assessed cognitive

\author{
K. N. Price \\ IBCSG Statistical Center, Frontier Science and Technology \\ Research Foundation, Dana-Farber Cancer Institute, 44 Binney \\ Street, Mailstop CLSB 11007, Boston, MA, USA \\ e-mail: price@jimmy.harvard.edu \\ R. D. Gelber \\ IBCSG Statistical Center, Frontier Science and Technology \\ Research Foundation, Dana-Farber Cancer Institute, \\ Boston, MA, USA \\ e-mail: gelber@jimmy.harvard.edu \\ J. Bernhard ( $\square)$ \\ IBCSG Coordinating Center, Effingerstrasse 40, \\ 3008 Bern, Switzerland \\ e-mail: juerg.bernhard@ibcsg.org \\ J. Bernhard \\ Department of Medical Oncology, Inselspital, \\ Bern University Hospital, Bern, Switzerland
}

function at Y5 (during the fifth year on endocrine therapy) and Y6 (approximately 1 year after cessation of therapy). Cross-sectional Y5 data, showing that patients on letrozole had better overall cognitive function than those on tamoxifen, have been previously reported [6]. We now report longitudinal data assessing cognitive changes between Y5 and Y6. The substudy protocol was approved by the local and International Breast Cancer Study Group (IBCSG) ethics committees and the required health authorities of each participating center. All the patients gave informed consent to participate in the substudy and parent study.

Objective cognitive function was assessed using a brief computerized test battery (CogState Ltd; http://www. cogstate.com) which is free from practice effects [10-13]. Details of the test battery are given in Table 1. A composite score, representing the average standardized score of each task for each individual, was prospectively defined as the primary endpoint.

Scores for each task were transformed, then standardized according to age-specific norms (Z-scores) [14]. A positive $Z$-score indicates a patient performed better than average for her age group. The composite score was calculated by the mean of the $Z$-scores for all tasks. For five patients who were missing data on some individual tasks, the mean of the scores of the completed tasks was taken as their composite score. A positive difference in the composite score from $\mathrm{Y} 5$ to $\mathrm{Y} 6$ indicates that cognitive function improved.

Change in cognitive function from $\mathrm{Y} 5$ to $\mathrm{Y} 6$ was assessed using the Wilcoxon signed-rank test, first for all the patients and then separately for each treatment group. No substantial normality violations were noted. The effect of endocrine treatment on change in cognitive function was assessed using two-way ANOVA controlling for the effect of language. Descriptive statistics of change in performance (mean, SD, and effect size) were calculated per treatment group for each task. Effect size is defined as the difference between Y6 and Y5 measurements divided by the standard deviation of the difference.

The effect of treatment on the changes in cognitive function was also assessed nonparametrically using the stratified Wilcoxon Rank Sum test (adjusted for language). To account for potential imbalances between treatment groups, a linear model was created for the CogState composite score to further evaluate the treatment effect using a stepwise selection procedure with the following covariates: treatment, language, age, chemotherapy received, tumor size, history of depression, treatment for depression at Y5, time between assessments, and ECOG performance status at Y5. Treatment and language were forced into the model. Comparisons of scores between the two monotherapy arms, and between monotherapy and sequential therapy arms for 
Fig. 1 CONSORT diagram of the BIG 1-98 Cognitive Function Substudy. $T$ tamoxifen for 5 years, $L$ letrozole for 5 years, $T \rightarrow L$ tamoxifen for 2 years followed by letrozole for three years, $L \rightarrow T$ letrozole for 2 years followed by tamoxifen for 3 years, ET endocrine therapy, $Y 5$ cognitive function assessment taken at the end of 5 years of ET, $Y 6$ cognitive function assessment taken approximately 1 year after completion of ET
Table 1 Cogstate cognitive function test battery

\begin{tabular}{|c|c|c|c|}
\hline Task & $\begin{array}{l}\text { Verbal/ } \\
\text { non-verbal }\end{array}$ & Cognitive domain & Outcome measured \\
\hline Detection & $\begin{array}{l}\text { Non- } \\
\text { verbal }\end{array}$ & Speed of psychomotor function & Performance speed \\
\hline Identification and monitoring & $\begin{array}{l}\text { Non- } \\
\text { verbal }\end{array}$ & Visual attention & Performance speed \\
\hline Learning & $\begin{array}{l}\text { Non- } \\
\text { verbal }\end{array}$ & Visual learning and memory & Performance accuracy \\
\hline Memory & $\begin{array}{l}\text { Non- } \\
\text { verbal }\end{array}$ & Attention and working memory & Performance accuracy \\
\hline Shopping list ${ }^{\mathrm{a}}$ & Verbal & Verbal learning and memory & Number of correct responses \\
\hline Shopping list delayed recall ${ }^{\mathrm{a}}$ & Verbal & Verbal learning and memory & Number of correct responses \\
\hline
\end{tabular}

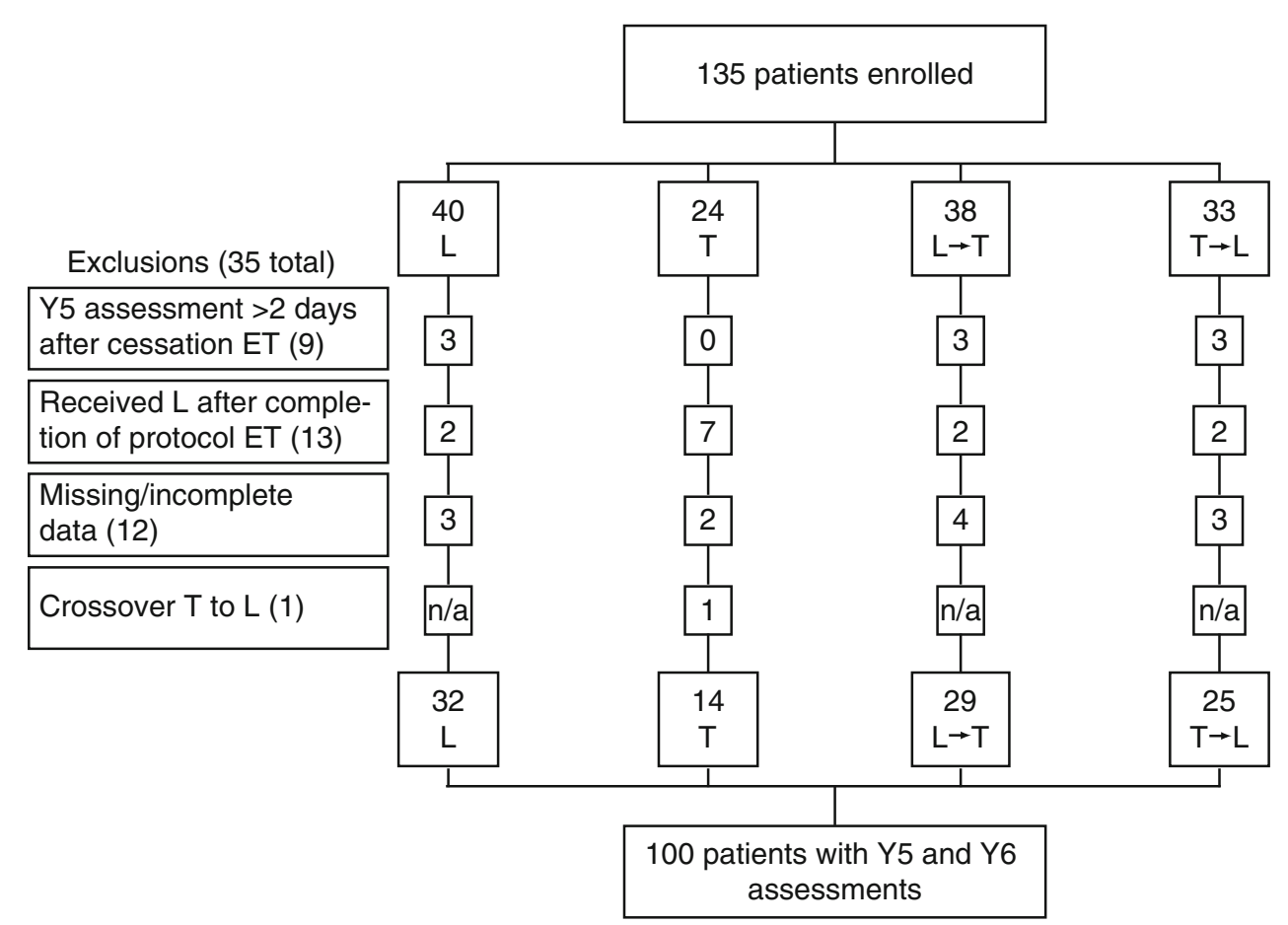

a Subjects were required to learn a 12-item shopping list and recall it after $20 \mathrm{~min}$ tamoxifen and for letrozole, respectively, were based on two-way ANOVA controlling for language. All $P$ values were based on two-sided tests. A $P$ value $<0.05$ indicates statistical significance.

Of the 135 patients recruited to this substudy, 35 were ineligible for this analysis (Fig. 1), leaving 100 patients as eligible for inclusion. The Y6 assessment was undertaken a median of 365.5 days (range 191-699 days) after ceasing protocol endocrine therapy.

\section{Results}

There was significant improvement in cognition, as measured by the change in composite score, from Y5 to Y6 (median of change $=0.22$, effect size $=0.53, P<0.0001$ ) (Fig. 2, Table 2). This finding was consistent in women taking either tamoxifen or letrozole at Y5 (median of change $=0.20$, effect size $=0.54$, and $P=0.0006$; or median of change $=0.23$, effect size $=0.53$, and $\mathrm{P}=0.0002$, respectively) and across all cognitive tasks (though not statistically significant for the learning task) (Table 2). The effect size, defined as the difference in score between Y5 and Y6 divided by the standard deviation of the difference, was small for the individual tasks (range 0.17-0.35) and moderate for the change in overall cognition as measured by the composite score (0.53). After adjusting for language and any significant covariates, the change in cognitive function (Y6-Y5) of patients taking letrozole at Y5 was not different from those taking tamoxifen at Y5. Exploratory analyses revealed no 


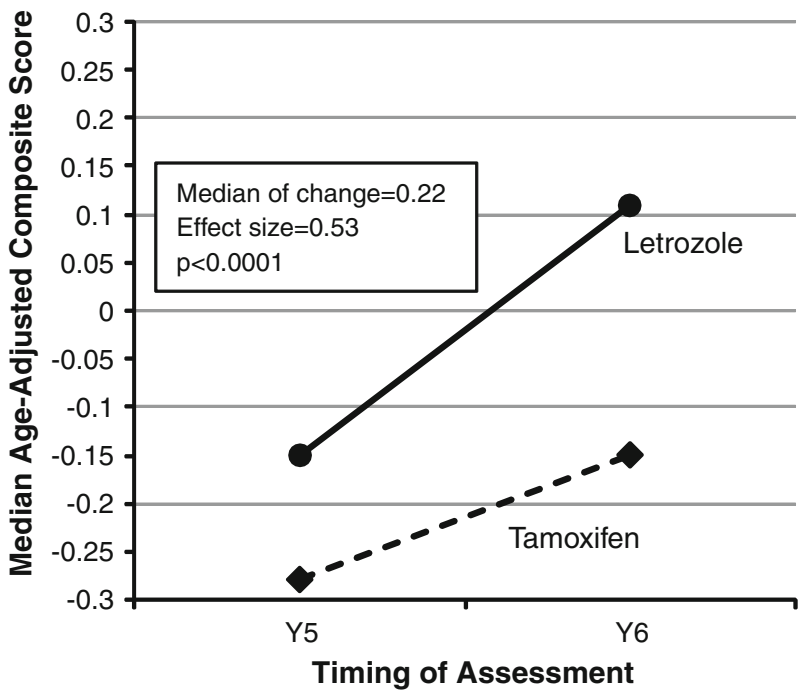

Fig. 2 Change in median age-adjusted composite score from the assessment taken at the end of endocrine therapy $(Y 5)$ to the assessment taken approximately 1 year after completion of endocrine therapy (YO) according to endocrine therapy received, showing significant improvement in cognition, as measured by the composite score, from $Y 5$ to $Y 6$

differences in the change in cognitive function (Y6-Y5) between the monotherapy arms or the monotherapy versus sequential arms.

\section{Discussion}

In this substudy, cognitive function was better approximately 1 year after cessation of adjuvant endocrine therapy as compared with the fifth year on therapy. For the composite score, this improvement (effect size $=0.53$ ) was, by convention, moderate in magnitude. Changes in cognitive function of a similar magnitude have been observed in healthy adults given methylphenidate for cognitive enhancement $[15,16]$. In addition, stressing the clinical relevance of our findings, the effect size observed is larger than that required by the FDA for approval of drugs that enhance cognition in diseases such as schizophrenia [17]. Although there was no untreated control group in the randomized BIG 1-98 trial, the improvement is not thought to be because of practice effects as these do not operate in the CogState test battery, and the magnitude of improvement is too large. Cognitive function was not assessed before starting endocrine therapy, and so we cannot calculate how cognition 1 year after cessation of therapy compares with baseline cognitive function before commencing adjuvant endocrine therapy. Nevertheless, this study suggests that if adjuvant endocrine therapy affects cognition in postmenopausal women, that effect is at least partly reversible with cessation of therapy, which is a

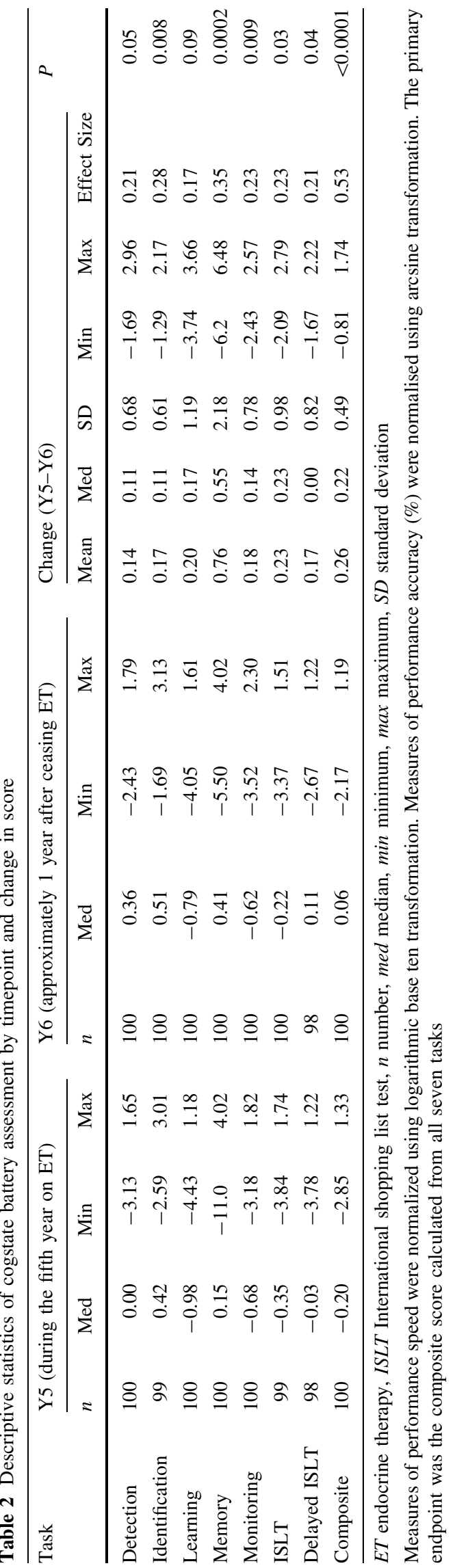


relevant and new finding for postmenopausal women with hormone receptor positive breast cancer.

\begin{abstract}
Acknowledgment We thank the patients who participated in this trial, collaborators, and funding sources. Acknowledgment for respective individuals involved in the various groups is given in the Appendix. This work was supported by Novartis and coordinated by IBCSG. Support for the IBCSG: Swedish Cancer Society; The Cancer Council Australia; Australian New Zealand Breast Cancer Trials Group; Frontier Science and Technology Research Foundation; Swiss Group for Clinical Cancer Research (SAKK); National Cancer Institute at the National Institutes of Health (Grant number CA75362); Cancer Research Switzerland/Oncosuisse; and the Foundation for Clinical Cancer Research of Eastern Switzerland (OSKK); The Cancer Council Victoria, Dr. John Colebatch Clinical Research Fellowship (to K.A.P).
\end{abstract}

Conflict of interest Financial disclosures: The substudy was funded by Novartis. Novartis contracted with the International Breast Cancer Study Group (IBCSG) for provision of services related to the conduct and management of the trial. Dr. Thürlimann owns stock in Novartis; Dr. Cardoso has received consulting and/or lecture fees from Novartis, Dr. Thompson and Dr. Goldhirsch have received honoraria from Novartis. The remaining authors have no conflicts to report.

\section{Appendix}

BIG 1-98 collaborative group participants

Steering Committee: B. Thürlimann (Chair), S. Aebi, L. Blacher, A. S. Coates, T. Cufer, J. F. Forbes, R. D. Gelber, A. Giobbie-Hurder, A. Goldhirsch, A. Hiltbrunner, S. B. Holmberg, R. Maibach, A. Martoni, L. Mauriac, G. McGrogan, H. T. Mouridsen, R. Paridaens, D. Phuong, K. N. Price, M. Rabaglio, B.B. Rasmussen, M.M. Regan, A. Santoro, I. E. Smith, A. Wardley, G. Viale. Novartis: H.

A. Chaudri-Ross, S. Segal, D. B. Evans, C. Sguotti

IBCSG Foundation Council (members from 1998 to 2008): S. Aebi, A. S. Coates, M. Colleoni, J. P. Collins, H. Cortés Funes, R. D. Gelber, A. Goldhirsch, M. Green, A. Hiltbrunner, S. B. Holmberg, P. Karlsson, I Kössler, I. Láng, J. Lindtner, F Paganetti M. de Stoppani, C.-M. Rudenstam, H.-J. Senn, R. Stahel, B. Thürlimann, A. Veronesi.

IBCSG Coordinating Center (Berne, Switzerland): A. Hiltbrunner (Director), M. Rabaglio, G. Egli, B. Ruepp, R. Maibach, N. Munarini, M. Castiglione.

Quality of Life Office (Berne, Switzerland): J Bernhard, K. Ribi, D. Gerber.

IBCSG Statistical Center (Boston, MA, USA): R. D. Gelber, K. N. Price, A. Giobbie-Hurder, Z. Sun, M.M. Regan, J. Aldridge, H. Huang.

IBCSG Data Management Center (FSTRF, Amherst, NY, USA): L. Blacher (Director of Data Management), T. Heckman Scolese (Coordinating Data Manager), J. Celano,
S. Fischer, S. Lippert, L. Mundy, K. Scott, M. Scott, J. Swick, L. Uhteg, D. Weinbaum, C. Westby, T. Zielinski.

Breast international group (BIG)

International breast cancer study group (IBCSG)

Australian New Zealand Breast Cancer Trials Group (ANZ BCTG): R. D. Snyder, J. F. Forbes, F. Boyle; ANZ BCTG Operations Office (Newcastle, Australia): D. Lindsay, D. Preece, J. Cowell, D. Talbot, A. Whipp.

Australia: The Cancer Council Victoria, Melbourne: K. Wysman, S. Vickery, N. Ranieri, B. Gleeson, B. Scher, F. Abell, R. Basser, R. Bell, B. Brady, D. Blakey, P. Briggs, I. Burns, P. Campbell, M. Chao, J. Chirgwin, B. Chua, K. Clarke, J. Collins, R. De Boer, J. C. Din, R. Doig, A. Dowling, R. Drummond, N. Efe, S. T. Fan, M. Francis, P. Francis, V. Ganju, P. Gibbs, G. Goss, M. Green, P. Gregory, J. Griffiths, I. Haines, M. Henderson, R. Holmes, P. James, J. Kiffler, M. Lehman, M. Leyden, L. Lim, G. Lindeman, R. Lynch, B. Mann, J. McKendrick, S. McLachlan, R. McLennan, G. Mitchell, S. Mitra, C. Murphy, I. Parker, K. Phillips, I. Porter, G. Richardson, J. Scarlet, S. Sewak, J. Shapiro, R. Snyder, R. Stanley, C. Steer, D. Stoney, A. Strickland, G. Toner, C. Underhill, K. White, M. White, A. Wirth, S. Wong; W P Holman Clinic, Prince of Wales Hospital, Sydney: C. Lewis, A. Zaat, B. Brigham, D. Goldstein, M. Friedlander.

New Zealand: Auckland Hospital, V. J. Harvey, J. Proctor, J. Millet, B. Joppa, B. Evans, W. Jones, M. McCrystal, D. Porter, P. Thompson, M. Vaughan.

Italy: Istituto Europeo di Oncologia, Milano: M. Colleoni, G. Viale, P. Veronesi, G. Peruzzotti, L. Corsetto, R. Ghisini, G. Renne, A. Luini, L. Orlando, R. Torrisi, A. Rocca, T. De Pas, E. Munzone, V. Galimberti, S. Zurrida, M. Intra, F. Nolé, R. Orecchia, G. Martinelli, F. de Braud, A. Goldhirsch.

Switzerland: Swiss Group for Clinical Cancer Research (SAKK): University Hospital Basel, Basel: C. Rochlitz, E Müller, R. Herrmann, D. Oertli, E. Wight, H. Moch; Institute of Oncology of Southern Switzerland: Ospedale San Giovanni, Bellinzona: J. Bernier, L. Bronz, F. Cavalli, E. Gallerani, A. Richetti, A. Franzetti; Ospedale Regionale di Lugano (Civico \& Italiano), Lugano: M. Conti-Beltraminelli, M. Ghielmini, T. Gyr, S. Mauri, P. C. Saletti; Ospedale Regionale Beata Vergine, Mendrisio: A. Goldhirsch, O. Pagani, R. Graffeo, M. Locatelli, S. Longhi, P.C. Rey, M. Ruggeri; Ospedale Regionale La Carità, Locarno: E. Zucca, D. Wyss; Istituto Cantonale di Patologia, Locarno: L. Mazzucchelli, E. Pedrinis, T. Rusca; Inselspital, Berne: S. Aebi, M. F. Fey, M. Castiglione, M. Rabaglio; Kantonsspital Olten, Olten: S. Aebi, M. F. Fey, M. Zuber, G. Beck; Kantonsspital St. Gallen, St. Gallen: B. Thürlimann, D. Köberle, F. Weisser, S. Mattmann, A. Müller, T. 
Cerny, B. Späti, M. Höfliger, G. Fürstenberger, B. Bolliger, C. Öhlschlegel, U. Lorenz, M. Bamert, J. Kehl-Blank, E. Vogel.

Belgium: Institut Jules Bordet, Bruxelles: J. M. Nogaret, V. Robberecht, V. Garreau, F. Cardoso.

United Kingdom: University of Dundee, Dundee: A. M. Thompson, B. Massie, J. A. Dewar.

\section{References}

1. McCarty KS Jr, Silva JS, Cox EB et al (1983) Relationship of age and menopausal status to estrogen receptor content in primary carcinoma of the breast. Ann Surg 197:123-127

2. Schilder CM, Seynaeve C, Beex WB et al (2010) Effects of tamoxifen and exemestane on cognitive functioning of postmenopausal patients with breast cancer: results from the neuropsychological side study of the tamoxifen and exemestane adjuvant multinational trial. J Clin Oncol 28:1294-1300

3. Collins B, Mackenzie J, Stewart A et al (2009) Cognitive effects of hormonal therapy in early stage breast cancer patients: a prospective study. Psychooncology 18:811-821

4. Bender CM, Sereika SM, Berga SL et al (2006) Cognitive impairment associated with adjuvant therapy in breast cancer. Psychooncology 15:422-430

5. Jenkins V, Shilling V, Fallowfield L et al (2004) Does hormone therapy for the treatment of breast cancer have a detrimental effect on memory and cognition? a pilot study. Psychooncology 13:61-66

6. Phillips KA, Ribi K, Sun Z et al (2010) Cognitive function in postmenopausal women receiving adjuvant letrozole or tamoxifen for breast cancer in the BIG 1-98 randomised trial. Breast 19:388-395

7. Jenkins V, Ambroisine LM, Atkins L et al (2008) Effects of anastrozole on cognitive performance in postmenopausal women: a randomized, double-blind chemoprevention trial (IBIS II). Lancet Oncol 9:953-961

8. BIG 1-98 Collaborative Group (2005) A comparison of letrozole and tamoxifen in postmenopausal women with early breast cancer. N Engl J Med 353:2747-2757

9. BIG 1-98 Collaborative Group (2009) Letrozole therapy alone or in sequence with tamoxifen in women with breast cancer. N Engl J Med 361:766-776

10. Vardy J, Wong K, Yi QL et al (2006) Assessing cognitive function in cancer patients. Support Care Cancer 14:1111-1118

11. Falleti MG, Maruff P, Collie A et al (2003) Qualitative similarities in cognitive impairment associated with $24 \mathrm{~h}$ of sustained wakefulness and a blood alcohol concentration of $0.05 \%$. J Sleep Res 12:265-274

12. Snyder PJ, Werth J, Giordani B et al (2005) A method for determining the magnitude of change across difference cognitive functions in clinical trials: the effects of acute administration of two different doses of alprazolam. Hum Psychopharmacol 20:263-273

13. Collie A, Darby D, Maruff P (2001) Computerized cognitive assessment of athletes with sports related head injury. Br J Sports Med 35:279-302

14. Maruff P, Thomas E, Cysique L et al (2009) Validity of the CogState brief battery: relationship to standardized tests and sensitivity to cognitive impairment in mild traumatic brain injury, schizophrenia, and AIDS dementia complex. Arch Clin Neuropsychol 24:165-178

15. Silber BY, Croft RJ, Papafotiou K, Stough C (2006) The acute effects of d-amphetamine and methamphetamine on attention and psychomotor performance. Psychopharmacology 187:154-169

16. Fillmore MT, Kelly TH, Martin CA (2005) Effects of damphetamine in human models of information processing and inhibitory control. Drug Alcohol Depend 77:151-159

17. Buchanan RW, Keefe RS, Umbricht D et al The FDA-NIMHMATRICS guidelines for clinical trial design of cognitiveenhancing drugs: what do we know 5 years later? Schizophr Bull (in press) 